\title{
Castellated Structures for ITER: Differences of Impurity Deposition and Fuel Accumulation in the Toroidal and Poloidal Gaps
}

\author{
A. Litnovsky ${ }^{1}$, V. Philipps ${ }^{1}$, P. Wienhold ${ }^{1}$, K. Krieger ${ }^{2}$, A. Kirschner ${ }^{1}$, D. Borodin ${ }^{1}$, \\ G. Sergienko ${ }^{1}$, O. Schmitz ${ }^{1}$, A. Kreter ${ }^{1}$, U. Samm ${ }^{1}$ and TEXTOR Team, \\ S.Richter ${ }^{3}$ and U. Breuer ${ }^{4}$ \\ ${ }^{1}$ Institut für Energieforschung - Plasmaphysik, Forschungszentrum Jülich, Trilateral Euregio Cluster, \\ Association EURATOM- FZ Jülich, D-52425 Jülich, Germany \\ ${ }^{2}$ Max-Planck-Institut für Plasmaphysik, D-85748, Garching, Germany \\ ${ }^{3}$ Gemeinschaftslabor für Elektronenmikroskopie, RWTH Aachen, D-52056 Aachen Germany; \\ ${ }^{4}$ Zentralabteilung für Chemische Analysen, Forschungszentrum Jülich, D-52425 Jülich, Germany.
}

\begin{abstract}
Castellation is foreseen for the first wall and divertor area in ITER. The concern of the fuel accumulation and impurity deposition in the gaps of castellated structures calls for dedicated studies.

Recently, a tungsten castellated limiter with rectangular and roof-like shaped cells was exposed to the SOL plasmas in TEXTOR. After exposure, roughly two times less fuel was found in the gaps between the shaped cells whereas the difference in carbon deposition was less pronounced. Up to 70 at. \% of tungsten was found intermixed in the deposited layers in the gaps. The metal fraction in the deposit decreases rapidly with a depth of the gap. Modeling of carbon deposition in poloidal gaps has provided a qualitative agreement with an experiment. Misalignment of toroidal gaps with respect to the magnetic field lines has led to the significant anisotropy of $\mathrm{C}$ and $\mathrm{D}$ distribution in the gaps.
\end{abstract}

PACS: 52.55.Fa; 52.40.Hf; 52.25.Vy

JNM Keywords: Plasma-material interactions (P0500), Surface effects (S1300), Carbon (C0100).

Corresponding and presenting author: Dr. Andrey Litnovsky

Corresponding and presenting author address: Institut für Energieforschung - Plasmaphysik, Forschungszentrum Jülich, D-52425 Jülich, Germany

Corresponding and presenting author E-mail: a.litnovsky@fz-juelich.de 


\section{Introduction}

In ITER the armor of the first wall and divertor area will be castellated to maintain the thermomechanical durability of the machine [1,2]. Given the difficulties in fuel removal [3-5], there is a concern that the radioactive fuel will be accumulated in the gaps of such a castellation [6-9]. Dedicated studies addressing the performance of castellated structures under plasma impact are ongoing on several tokamaks [10-12]. Series of experimental investigations with ITER-like castellated samples were performed in TEXTOR along with dedicated modeling to address the issues of carbon transport and fuel accumulation in the gaps [13-15] and on molten layer formation and its impact on the performance of castellation [16]. In a recent study [17] an attempt was made to optimize the shape of the castellation cells in order to minimize the carbon transport and fuel deposition in the gaps and the first comparative results were presented. In this paper we provide more in-depth analyses of the deposition in gaps, studies on metal intermixing in the deposits along with the first modeling results.

Experimental: design of the castellated limiter, exposure in TEXTOR, nomenclature of castellation cells and post-exposure analyses

The design of a castellated limiter (Fig.1) is described in details in [17]. Two types of castellations were installed on the double-roof limiter: shaped castellation with the roof-like cells as shown on Fig. 1b with dimensions of 10x10x12/15 mm and the castellation with rectangular cells of 10x10x15 mm. Each castellation had 2 rows with 3 cells in each. The gap in between the cells was 0.5 mm wide.

The limiter was exposed in the SOL of TEXTOR using the Limiter Lock system [18] at the radial distance of $\mathrm{R}=46.5 \mathrm{~cm}, 0.5 \mathrm{~cm}$ outside the Last Closed Flux Surface (LCFS). 16 repetitive identical NBI-heated discharges were performed with total plasma duration of 112 seconds. Several diagnostics were applied during the experiment to measure the plasma parameters as described in [17]. The bulk temperature of test limiter as measured with thermocouples was in the range of $200-250^{\circ} \mathrm{C}$, whereas the surface temperature of the uppermost cells rose up to $1100^{\circ} \mathrm{C}$ during the discharge. Three discharges were accompanied with undesirable loss of vertical plasma control which resulted to thermal excursions of the uppermost cells up to $1500^{\circ} \mathrm{C}$.

In this paper we are keeping the nomenclature introduced in [17]: the gaps oriented along the poloidal and toroidal field directions we name as poloidal and toroidal gaps respectively, a shaped castellation was facing an ion drift side, therefore an "i" is introduced to identify the shaped cells. For the rectangular castellation facing an electron field side an " $\mathrm{e}$ " is introduced similarly. The rows of castellation structures are numbered with 1 and 2, starting with the plasma-closest row and the cells within a row are marked with letters from "a" to "c" as can be seen from the Fig.1a.

Several surface and elemental analyses were made in gaps, plasma-facing top surfaces and on the gap holder. Line scans in the depth of gaps were made using Electron Probe MicroAnalysis (EPMA) technique at the Reinisch Westfälische Technische Hochshule (RWTH, Aachen). Line scans were also 
made using the Nuclear Reaction Analysis (NRA) technique at the IPP Garching, using the BOMBARDINO device. Secondary-Ion Mass Spectrometry (SIMS) measurements were made on the top surfaces, gaps and in the bottom of both castellation using the double-beam ION-ToF 4 device at the Forschungszentrum Jülich. The SIMS measurements were calibrated using the DEKTAK 6M stylus profiler at the Forschungszentrum Jülich, so that the sputter speed were known for both used $\mathrm{O}$ and Cs beams within an accuracy of $20 \%$.

\section{Results and analyses}

Poloidal gaps

\section{C transport and $D$ accumulation}

Following the initial estimates provided in [17], the total amount of carbon and deuterium in the poloidal gaps was précised using the integration along the NRA scan with supporting EPMA and SIMS measurements as shown in Fig .2. The respective total values of $\mathrm{C}$ and $\mathrm{D}$ in the gaps of both shaped and rectangular cells are presented in the table 1. From the table it can be seen that the poloidal gaps of shaped cells indeed contain roughly a factor of 2 less deuterium, showing an advantageous feature of the new geometry. At the same time, a more precise accounting of the amount of $\mathrm{C}$ in the gaps of rectangular and shaped cells revealed less pronounced advantages of the shaped geometry, in the response to the first estimates reported in [17] which were based on the peak values of $\mathrm{C}$ deposition in gaps. In the new accounting the shape of the overall deposition profile along the gap was considered: the profiles of deposition in the rectangular cell featured indeed the highest peak values, but they were peaked near the plasma-closest edges only while the deposition patterns in the gaps of shaped cells were smoother (Fig. 2a).

The overall $\mathrm{D} / \mathrm{C}$ ratio is rather small varying between $0.5 \%$ and $3.0 \%$ due to the temperature excursions caused by the plasma load during the exposure.

\section{Metal mixing in the deposits}

The quantification of the observed metal intermixing reported in [17] has been made based on the comparison of the deposit thickness derived from the EPMA measurements and direct measurements made by DEKTAK profiler. The algorithm of the quantification is described in details [15]. Results shown in Fig. 3 demonstrate that metal intermixing is significant reaching 70 at. \% of $\mathrm{W}$ in the deposit for the plasma-closest edges of the gaps. The metal fraction in the deposit decreases rather rapidly with the depth of the gap.

\section{Modeling of carbon deposition in the gaps}

The modeling has been started to reveal the main mechanisms responsible for the deposition in the gaps. The modeling aims at first to reproduce the deposition patterns observed in the experiments. Runs were made with a simple particle reflection model, as was used in [15] for three particle reflection coefficients $\mathrm{R}=0, \mathrm{R}=0.5$ and $\mathrm{R}=0.9 .30 .000$ carbon atoms were started from the three source locations shown in the Fig.4b for the two different geometries. The results are plotted in Fig. 4a showing the 
dependence of the number of deposited atoms on the distance along the gap for $\mathrm{R}=0.5$. As it can be seen, the approximate form of measured deposition pattern presented in Fig.2a can be qualitatively reproduced assuming this reflection coefficient. However, the absolute amount of carbon deposited in the gap of the shaped cell is significantly lower than in the rectangular one. This result does not match the data inferred from experiment (Table 1). A probable reason for this is that we assume equally strong particle sources for both cell geometries. In reality, for the shaped cells the part of the roof top surface (segment $\mathrm{S}$ on Fig.4b) will act as a particle source which is expected to be much stronger than that in the rectangular geometry (segment R on Fig.4a). The width of source for rectangular cells is $0.5 \mathrm{~mm}$ whereas the width of source for shaped cells is of order of $6 \mathrm{~mm}$. A further upgrade of the model is therefore underway and will be discussed later in the paper.

\section{Toroidal gaps}

\section{C transport and $D$ accumulation}

As reported in [17] very inhomogeneous deposition patterns were found in toroidal gaps for both cell geometries. Moreover, a similar deposition pattern is observed on the same sides of toroidal gaps, independently on shaping, as presented on the photographs in Fig. 5a. (e.g. compare the patterns observed for both geometries for case V). An example of the NRA line scan is presented in Fig. 5a for a toroidal gap of shaped cells is $2 a$ and is $2 b$. There is a visible significant difference in the deposition pattern on both sides of this gap (lower two photographs in Fig. 5a). The total amount of C and D differs much depending on the side of the same toroidal gap. The most probable reason for such a difference is the imperfect alignment of the toroidal gap with respect to the toroidal field direction. This misalignment as shown with an arrow in Fig.5b has led to the occurrence of the areas in the toroidal gaps with a direct view of the plasma. This has caused erosion of the uppermost edges of plasma-viewing sides of toroidal gaps (uppermost edges of gaps on photographs for case V in Fig.5a) in a full similarity with plasma-open sides of poloidal gaps (see Fig.2 case A for comparison). The line-integrated total amount of C and D deposited on the plasma-shadowed side of this toroidal gap is a factor of 2 more than that on the plasma-viewing part. Such an inhomogenity may arise from the fact that the gap size of $0.5 \mathrm{~mm}$ is smaller than the characteristic gyroradii of both $\mathrm{C}$ and $\mathrm{D}$ ions ranging from 1 to $1.5 \mathrm{~mm}$ under experimental conditions, which will likely cause the shadowing of the one side of the gap. In addition, the alignment of the toroidal gaps with respect to the magnetic field is also important, though in ITER there will be no opportunity to maintain the perfect alignment of gaps to the magnetic field. Quantification of the carbon deposits using only the line-scans is not justified because of the very inhomogeneous deposition patterns in the toroidal gaps. The quantification requires time-taking procedure of the 2D real deposition pattern as shown on the photographs of Fig.5a. The first estimates using the 2D deposition pattern demonstrate that not more than $30 \%$ of carbon was deposited in toroidal gaps in comparison to poloidal ones. The detailed comparative analysis of the total amount of deposited carbon and accumulated fuel in the poloidal and toroidal gaps will be reported later.

\section{Deposition on the bottom of gaps: first investigations}


First investigations made with SIMS and DEKTAK techniques reveal the existence of deposits with up to $200 \mathrm{~nm}$ thickness on the castellation holder at the bottom of the gaps. These data should be compared with up to $\sim 500 \mathrm{~nm}$ thick deposits detected on the sides of gaps. While the analyses are still ongoing, these observations will certainly influence the modeling of deposition patterns in the gap. Obviously the observed deposition on the bottom cannot be reproduced using the present simple model. A further upgrade of the model will include angular-dependent reflection coefficients which likely to smoothen the deposition patterns and may provide more particles to the bottom of gaps.

\section{Conclusion and discussion}

Detailed analyses of the total deuterium inventory in the poloidal gaps revealed the advantages of using shaped castellation: roughly a factor of 2 less deuterium was found in the gaps of shaped cells. At the same time, the carbon transport into the shaped gaps was only marginally smaller, than that into rectangular ones. This outlines the necessity for further optimization of the shaping.

Up to 70 at. \% W was found intermixed in the deposits near the plasma-closest edges of the poloidal gaps. The metal fraction decreases rapidly with the depth of the gap and can be neglected if the distance from uppermost edge of the gap exceeds $3 \mathrm{~mm}$. The formation of the mixed metal-containing deposits will deteriorate the cleaning efficiency in the gaps of the castellated structures in ITER.

Modeling attempts to simulate the observed deposition pattern using the same assumptions as reported in [15] resulted in partial success only: a rough qualitative agreement between modeling and experimental data was achieved with a carbon atom reflection coefficient of $50 \%$.

A misalignment of the toroidal gaps with respect to the toroidal magnetic field direction has caused an asymmetry of carbon and deuterium distributions in the toroidal gaps: more C and D were found on plasma-shadowed sides of gaps independently on their shaping. This may be due to the fact that the width of gap is smaller than the gyroradii of $\mathrm{C}$ and $\mathrm{D}$ atoms leading the shadowing of one side of toroidal gaps independently of their geometry. In addition, the effect of alignment of castellation with respect of field lines is important, although the misalignment is unlikely to be avoided in ITER. Because of the very inhomogeneous deposition patterns in toroidal gaps, the estimates of the total $\mathrm{C}$ amount cannot be done by integration and scaling up of the line-scans, like it was made in poloidal gaps. A more complicated accounting of the $\mathrm{C} / \mathrm{D}$ amounts using the real shape of a deposition is underway. The first results of this accounting demonstrate that toroidal gaps contain at least $30 \%$ more carbon than poloidal ones and thus by any means cannot be neglected in the analyses of integral carbon and fuel content in the gaps.

Significant deposition was observed at the bottom of gaps on the holder plate. The observed phenomena cannot be reproduced using the simple assumptions with fixed reflection coefficients calling for the further development of more sophisticated algorithms including:

- Angle-dependent reflection coefficient;

- Larger particle source in case of shaped cells in comparison to rectangular ones;

- Neutral gas generation at the bottom of a gap;

- Better understanding of plasma parameters inside the gaps. 


\section{Acknowledgments}

The authors would like to express their sincere gratitude to H. Reimer, M. Freisinger, W. Müller and TEXTOR team for help and support. We are also grateful to Mrs. A. Stärk from the Central Department of Chemical Analyses of the Forschungszentrum Jülich for the SIMS data and to Mr. M. Spähn from RWTH Aachen for EPMA measurements. This work is being performed within the research program of the European Task Force on Plasma-Wall Interactions. 
References:

1. A Review of ITER Technology R\&D, Fus. Eng. and Design (spec. issue) 55 (2-3) 2001 Ch. 3.3 and 3.4;

2. W. Daenner, M. Merola, P. Lorenzetto, A. Peacock, I. Bobin-Vastra, L. Briottet, P. Bucci, D. Conchon, A. Erskine, F. Escourbiac, M. Febvre, M. Grattarola, C.G. Hjorth, G. Hofmann, A. Ilzhoefer, K. Lill, A. Lind, J. Linke, W. Richards, E. Rigal, M. Roedig, F. Saint-Antonin, B. Schedler, J. Schlosser, S. Tahtinen and E. Visca, Fus. Eng. and Design 61-62 (2002) 61;

3. P. Andrew, P.D. Brennan, J.P. Coad, J. Ehrenberg, M. Gadeberg, A. Gibson, D.L. Hillis, J. How, O.N. Jarvis, H. Jensen, R. Lasser, F. Marcus, R. Monk, P. Morgan, J. Orchard, A. Peacock, R. Pearce, M. Pick, A. Rossi, P. Schild, B. Schunke and D. Stork, Fusion Eng. Des. 47, (1999) 233;

4. C. H. Skinner, J. P. Coad and G. Federici, Phys. Scripta T111 (2004) 92;

5. G. Federici, J. N. Brooks, M. Iseli and C. H. Wu, Phys. Scripta T91 (2001) 76

6. D.G. Whyte, J.P. Coad, P. Franzen and H. Maier, Nucl. Fusion 39 (1999) 1025;

7. M. Rubel, J. P. Coad, P. Wienhold, G. Matthews, V. Philipps, M. Stamp and T. Tanabe, Phys. Scripta T111 (2004), 112;

8. W.R. Wampler, B.L. Doyle, S.R. Lee, A.E. Pontau, B.E. Mills, R.A. Causey, D. Buchenauer, H.F. Dylla, M.A. Ulrickson and P.H. LaMarche, J. Vac. Sci. Technol A6 (3) (1988) 2111.

9. T. Tanabe, K. Sugiyama, C.H. Skinner, N. Bekris, C.A. Gentile and J.P. Coad, Fus. Sci. and Technol. 48 (2005), 577;

10. K. Krieger, W. Jacob, D.L. Rudakov, R. Bastasz, G. Federici, A. Litnovsky, H. Maier, V. Rohde, G. Strohmayer, W.P. West, J. Whaley and C.P.C. Wong, J. Nucl. Mater., 363-365 (2007) 870;

11. C. Wong, D. Rudakov, J. P. Allain, R. Bastasz, N. Brooks, J. N. Brooks, R. Doerner, T.E. Evans, A. Hassanein,, W. Jacob, K. Krieger, A. Litnovsky, A. McLean, V. Philipps, A. Yu. Pigarov, W. Wampler, J. Watkins, W.P. West, J. Whaley and P. Wienhold, J. Nucl. Mater., 363-365 (2007) 276 ;

12. D. Rudakov, W. Jacob, K. Krieger, A. Litnovsky, V. Philipps, W. P. West, C. P. C. Wong, S. L. Allen, R. J. Bastasz, J. A. Boedo, N. H. Brooks, R. L. Boivin, G. De Temmerman, M. E. Fenstermacher, M. Groth, E. M. Hollmann, C. J. Lasnier, A. G. McLean, R. A. Moyer, 
P. C. Stangeby, W. R. Wampler, J. G. Watkins, P. Wienhold and J. Whaley Phys. Scr. T128 (2007) 29;

13. A. Litnovsky, V. Philipps, P. Wienhold, G. Sergienko, B. Emmoth, M. Rubel, U. Breuer and E. Wessel, J. Nucl. Mater. 337-339, 917;

14. A. Litnovsky, V. Philipps, P. Wienhold, G. Sergienko, A. Kreter, O. Schmitz, U. Samm, P. Karduck, M. Blome, B. Emmoth and M. Rubel Proc.of $32^{\text {nd }}$ EPS Conf. ECA Vol.29C (2005) P-1.015;

15. A. Litnovsky, V. Philipps, A. Kirschner, P. Wienhold, G. Sergienko, A. Kreter, U. Samm, O. Schmitz, K. Krieger, P. Karduck, M. Blome, B. Emmoth, M. Rubel, U. Breuer and A. Scholl, J. Nucl. Mater., 367-370 (2007) 1481;

16. G. Sergienko, B. Bazylev, A. Huber, A. Kreter, A. Litnovsky, M. Rubel, V. Philipps, A. Pospieszczyk, Ph. Mertens, U. Samm, B. Schweer, O. Schmitz and M. Tokar, J. Nucl. Mater., 363-365 (2007) 96;

17. A. Litnovsky, V. Philipps, P. Wienhold, K. Krieger, G. Sergienko, A. Kreter, O. Schmitz, U. Samm, Ph. Mertens, A. Kirschner, S. Droste, S. Richter, U. Breuer, A. Scholl, A. Besmehn and Y. Xu, Phys. Scr. T128 (2007) 45;

18. B. Schweer, S. Brezinsek, H.G. Esser, A. Huber, Ph. Mertens, S. Musso, V. Philipps, A. Pospieszczyk, U. Samm, G. Sergienko and P. Wienhold, Fus. Sci. and Technology, Vol. 47, Nr. 2 (2005) 138; 


\section{Figure captions:}

Figure $1 \mathrm{~A}$ view of a castellated limiter III after exposure with a nomenclature of cells (a), the geometry of cells (b) and the scheme of exposure (c).

Figure 2: a) Distribution of areal deuterium and carbon atom density along the depth of poloidal gap of the rectangular (er12a) and shaped (is12a) cells: 1) Carbon atom density distribution along the gap of rectangular cell er12a; 2) Deuterium atom density distribution along the gap of rectangular cell er12a; 3) Carbon atom density distribution along the gap of shaped cell is $12 \mathrm{a}$; 4) Deuterium atom density distribution along the gap of shaped cell is12a. Arrows show the direction of the line scan along the gap.

b) The gap geometry: A- plasma open side of the gap with respect to the impinging plasma flow, Bplasma shadowed side. The edge of the shaped cell is shown with a dashed line.

Figure 3. Quantified metal mixing in the deposited layers formed in poloidal gap of the rectangular cell (er12b). The numbers show the atomic percentage of the tungsten in the deposit.

Figure 4: a) Modeled distribution of the deposited carbon atoms along the poloidal gap of 1) rectangular and 2) shaped cells; b) the gap geometries used for modeling, the particle sources are shown with light dots on the plasma-open (right) sides of gaps: R) for the rectangular cells, S) for the shaped cells

Figure 5: a) Distribution of areal deuterium and carbon atom density along the depth of toroidal gap of shaped (is2ab) cell: 1) Carbon atom density distribution along the gap; 2) Deuterium atom density distribution along the gap. Arrows show the direction of the line scan along the gap.

b) The geometry of toroidal gaps: V - plasma-viewing side of the gap with respect to the impinging plasma flow/magnetic field lines, S- plasma shadowed side.

Table 1. Line-integrated deposition of carbon and deuterium in the poloidal gaps of rectangular (er12a) and shaped (is12a) cells, D/C ratio of the deposits and ratios of carbon and fuel accumulated in rectangular and shaped gaps of poloidal cells. 


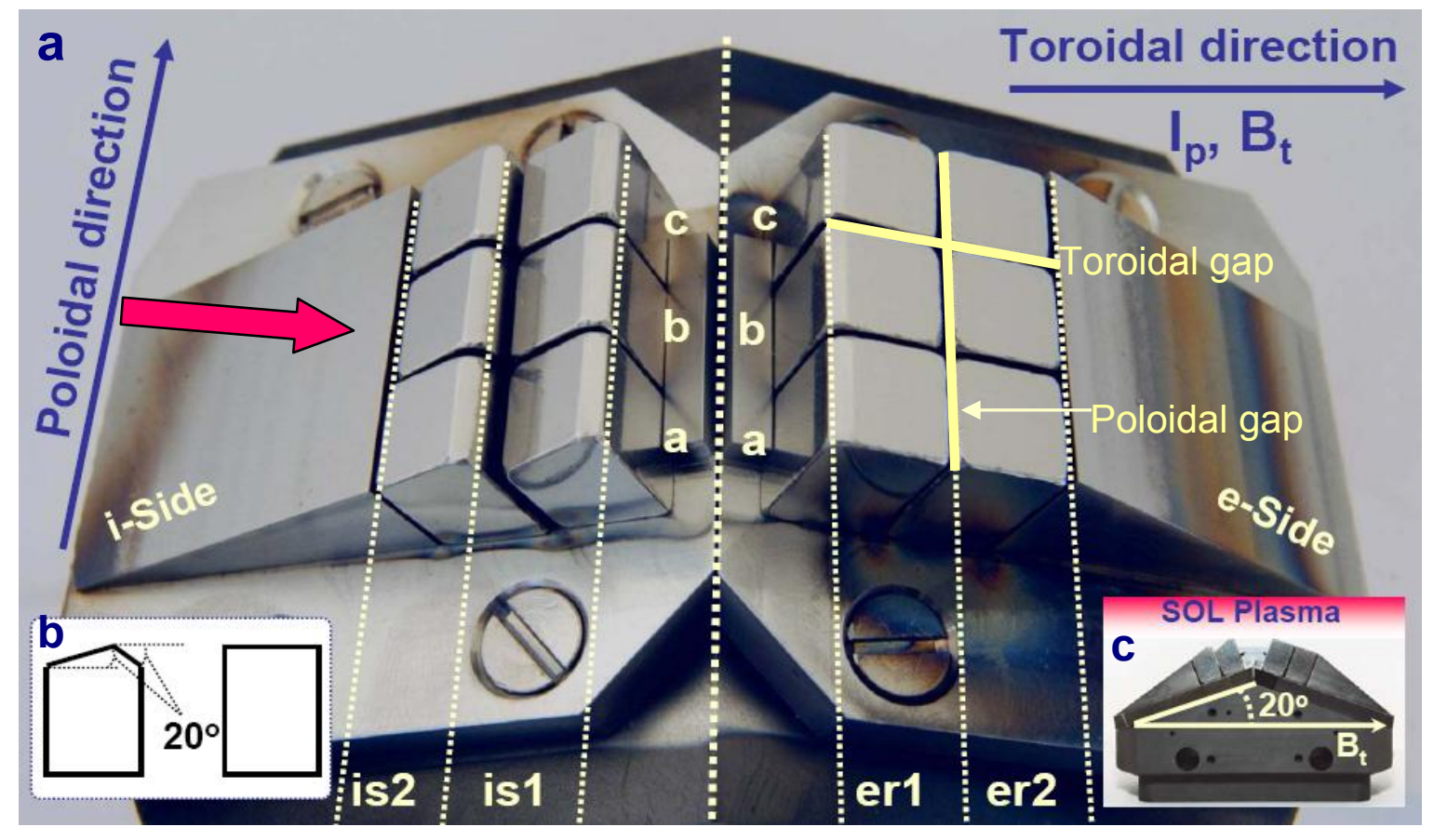

Figure 1: A view of a castellated limiter III after exposure with a nomenclature of cells (a), the geometry of cells (b) and the scheme of exposure (c). 


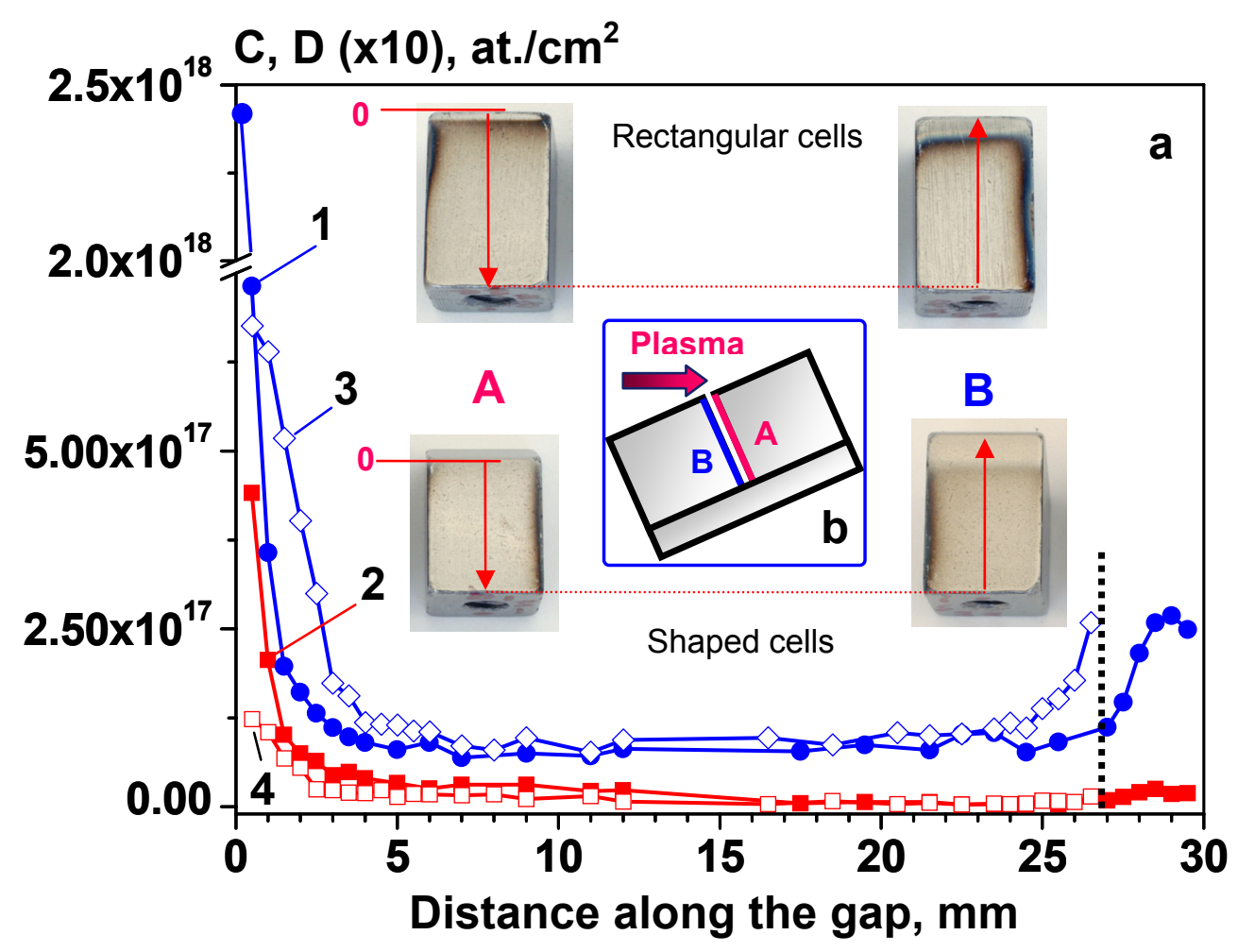

Figure 2: a) Distribution of areal deuterium and carbon atom density along the depth of poloidal gap of the rectangular (er12a) and shaped (is12a) cells: 1) Carbon atom density distribution along the gap of rectangular cell er12a; 2) Deuterium atom density distribution along the gap of rectangular cell er12a; 3) Carbon atom density distribution along the gap of shaped cell is12a; 4) Deuterium atom density distribution along the gap of shaped cell is12a. Arrows show the direction of the line scan along the gap.

b) The gap geometry: A- plasma open side of the gap with respect to the impinging plasma flow, Bplasma shadowed side. The edge of the shaped cell is shown with a dashed line. 
Table 1.

\begin{tabular}{|c|c|c|c|c|}
\hline \multicolumn{5}{|c|}{ Poloidal cells } \\
\hline $\begin{array}{l}\text { Total line } \\
\text { integrated }\end{array}$ & Rectangular cell & Shaped cell & Rectangular cell & Shaped cell \\
\hline & Plasma-open (A) & Plasma-open (A) & Plasma-shadowed (B) & Plasma-shadowed (B) \\
\hline $\mathrm{D}$ & $9.6^{*} 10^{14}$ & $5.4 * 10^{14}$ & $9.7 * 10^{15}$ & $3.0^{*} 10^{15}$ \\
\hline $\mathrm{C}$ & $1.4^{*} 10^{17}$ & $1.1 * 10^{17}$ & $4.6^{*} 10^{17}$ & $2.0^{*} 10^{17}$ \\
\hline $\mathrm{D} / \mathrm{C}, \%$ & 0.7 & 0.5 & 3.0 & 1.5 \\
\hline $\begin{array}{c}\text { Ratio } \\
\mathrm{D}_{\text {rect }} / \mathrm{D}_{\text {shaped }}\end{array}$ & \multicolumn{2}{|c|}{1.8} & \multicolumn{2}{|c|}{3.2} \\
\hline $\begin{array}{c}\text { Ratio } \\
\mathrm{C}_{\text {rect }} / \mathrm{C}_{\text {shaped }}\end{array}$ & \multicolumn{2}{|c|}{1.3} & \multicolumn{2}{|c|}{1.05} \\
\hline
\end{tabular}

Table 1. Line-integrated deposition of carbon and deuterium in the poloidal gaps of rectangular (er12a) and shaped (is12a) cells, $\mathrm{D} / \mathrm{C}$ ratio of the deposits and ratios of carbon and fuel accumulated in rectangular and shaped gaps of poloidal cells. 


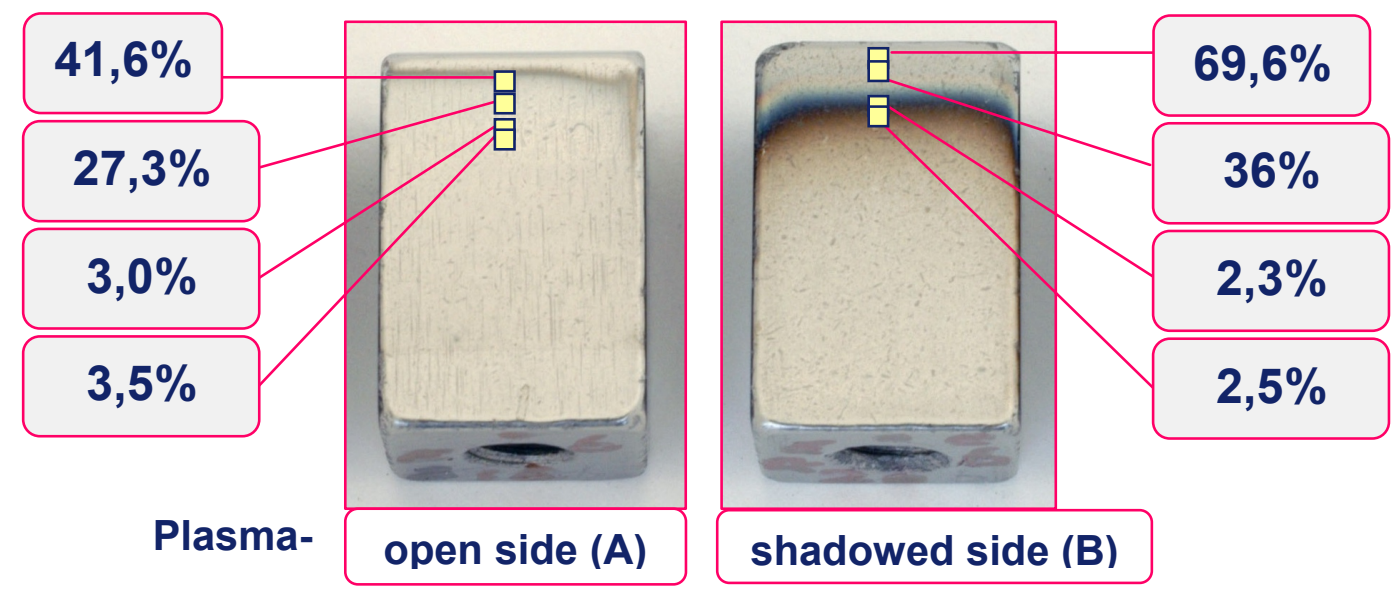

Figure 3. Quantified metal mixing in the deposited layers formed in poloidal gap of the rectangular cell (er12b). The numbers show the atomic percentage of the tungsten in the deposit. 


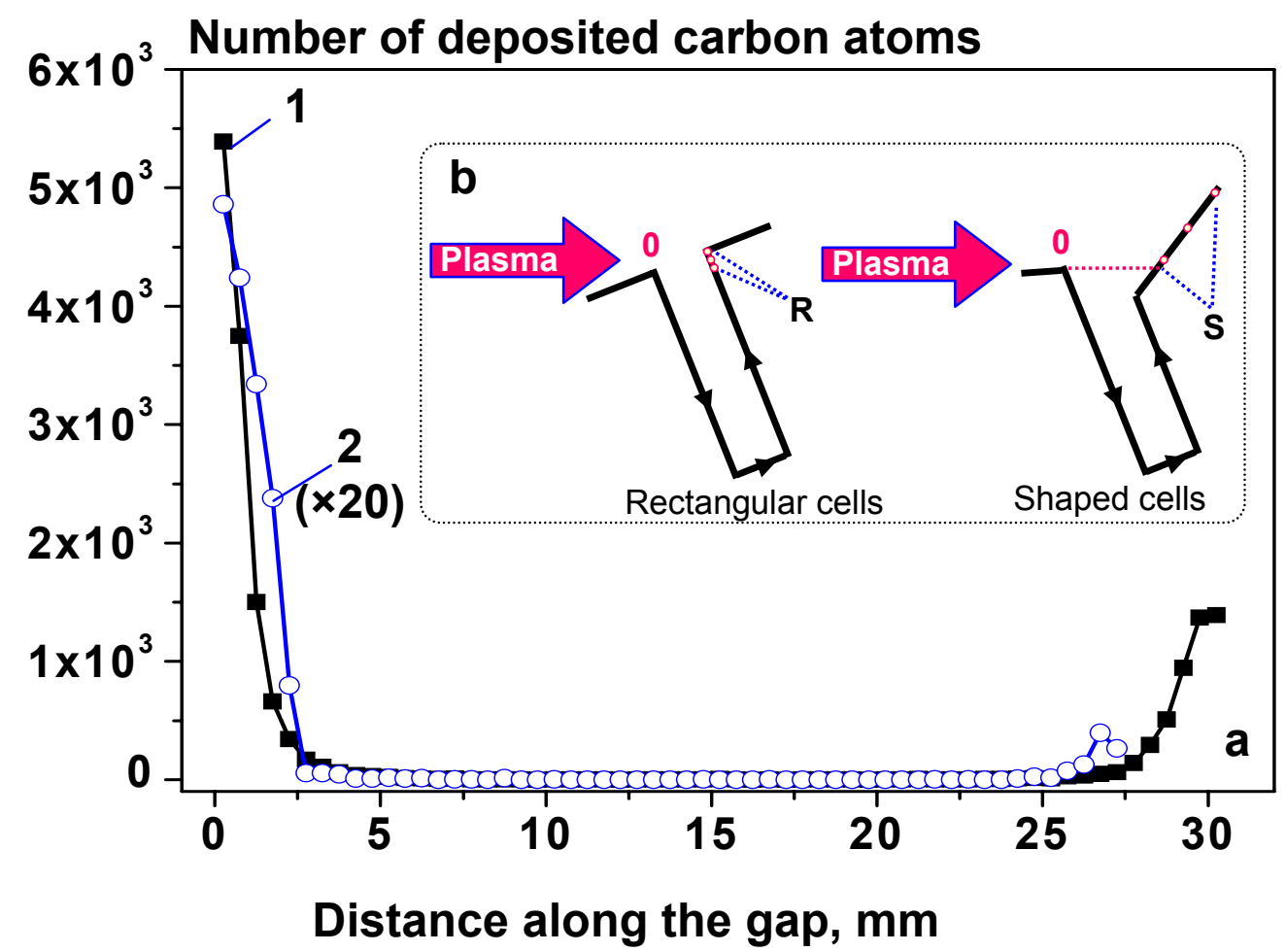

Figure 4: a) Modeled distribution of the deposited carbon atoms along the poloidal gap of 1) rectangular and 2) shaped cells; b) the gap geometries used for modeling, the particle sources are shown with light dots on the plasma-open (right) sides of gaps: R) for the rectangular cells, S) for the shaped cells 
C, D x10, at. $/ \mathrm{cm}^{2}$

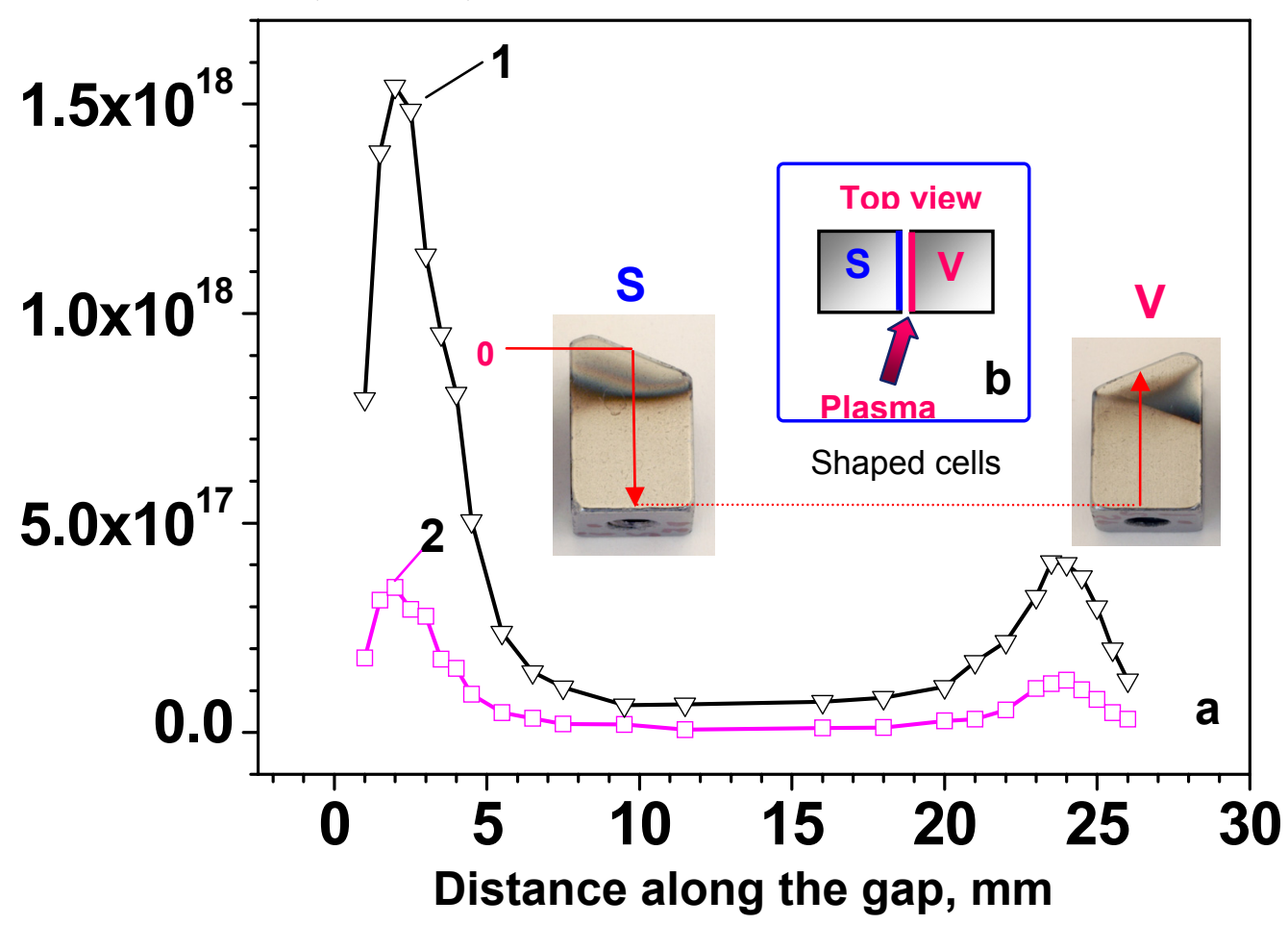

Figure 5: a) Distribution of areal deuterium and carbon atom density along the depth of toroidal gap of shaped (is2ab) cell: 1) Carbon atom density distribution along the gap; 2) Deuterium atom density distribution along the gap. Arrows show the direction of the line scan along the gap.

b) The geometry of toroidal gaps: V - plasma-viewing side of the gap with respect to the impinging plasma flow/magnetic field lines, S- plasma shadowed side. 